\title{
Prospecção do rendimento da carragena extraída da alga hypnea musciformis coletada na Praia do Coqueiro, estado do Piauí, submetida a quatro tratamentos prévios
}

\section{Yield prospection of carrageenan extracted from hypnea musciformis seaweed collected on the Coqueiro Beach, Piaui state, submitted to four previous treatments}

Emanuel Airton de Oliveira Farias'

1 Núcleo de Pesquisa em Biodiversidade e Biotecnologia, Universidade Federal do Piauí. Parnaíba-PI, Brasil.

Correspondência / Correspondence Emanuel Airton de Oliveira Farias E-mail: emanuel16airton@gmail.com

\section{Resumo}

A carragena é um polissacarídeo extraído da alga vermelha Hypnea musciformis e tem sido bastante estudada por sua abundância na costa de diversos países, incluindo Brasil. Tem sido utilizada na produção de produtos aquosos, cárnicos e lácteos, entre os quais se destacam géis de sobremesa, géis para consumo de produtos à base de peixes, sucos de frutas e concentrados em pó, rações para animais (enlatadas), temperos e molhos, pudins, sorvetes, achocolatados, entre uma infinidade de outros produtos. Dada sua larga aplicabilidade e a dependência cada vez maior das indústrias, a produção em larga escala de carragena, tanto através do cultivo, quanto de métodos de obtenção de maior rendimento deste polissacarídeo, são temas bastante abordados nos dias atuais. Neste sentido, o presente estudo buscou fazer uma comparação entre quatro métodos diferentes de extração da carragena, buscando evidenciar a melhor rota para obtenção do maior teor de rendimento. Nos métodos abordados, as algas passaram ou não por etapa de branqueamento e em seguida por secagem a sol ou estufa, nos seguintes tratamentos: (T1) algas secas ao sol e branqueadas; (T2) secas a sol e não branqueadas; (T3) secas em estufa e branqueadas; e (T4) secas em estufa sem etapa de branqueamento. Houve diferença no rendimento da carragena obtida pelos tratamentos pré-extração empregados, dos quais do T2 se obteve um rendimento de 21,63\%, sendo o mais satisfatório.

Palavras-chave: Extração. Polissacarídeos. Alga. Rendimento. 


\section{Abstract}

Carrageenan is a polysaccharide extracted from red seaweed Hypnea musciformis and has been widely studied due to its abundance on the coast of several countries, including Brazil. It has been used in the production of aqueous such as meats and dairy products, among which stand out dessert gels, gels products made from fish, fruit juices and powder concentrates, animal feed (canned), spices and sauces, puddings, ice cream, chocolate, among others. Due to the wide applicability of carrageenan and the industries are increasingly becoming dependent on this type of polysaccharide, the large-scale production of carrageenan, either through cultivation, as methods for obtaining higher yield of polysaccharide, are topics quite discussed currently. In this sense, this study aimed to make a comparison between four different methods of extraction of carrageenan, seeking to prove the best route to achieve the highest level of performance. In the methods discussed, the seaweed passed or not by the bleaching stage and subsequently drying by sun or heater, providing the following treatments: (T1), seaweed dried by and bleached; (T2) dried by sun and unbleached; (T3) dried by heater and bleached, and (T4) dried by heater without blanching step. There was difference in the yield of carrageenan obtained by these preextraction treatments, of which T2 obtained a yield of $21.63 \%$, being the most satisfactory.

Key words: Extraction. Polysaccharides. Seaweed. Yield.

\section{Introdução}

Os polissacarídeos extraídos das algas possuem características que os diferenciam dos demais encontrados nos vegetais superiores, principalmente devido à presença de unidades de 3,6 anidrogalactose de grupos sulfato. ${ }^{1}$ Dentre esses polissacarídeos naturais, podemos destacar a carragena, que tem sido amplamente investigada, sobretudo devido a sua biocompatibilidade e atoxidade.

As carragenas podem ser encontradas em algumas algas do tipo Rhodophyceae e são bastante conhecidas por possuírem propriedades gelificantes, além de serem demasiadamente utilizadas na indústria alimentícia e farmacêutica, como agentes de gelificação, espessamento ou estabilização. Quimicamente, as carragenas são 
poligalactanos, ou seja, polímeros sulfatados de moléculas alternadas de D-galactose e 3-6 anidro-D-galactose (3,6-AG) unidas por ligações $\alpha$ (1-3) e $\beta$ (1-4) glicosídicas. ${ }^{2}$

Pesquisas mostram que é possível extrair, dependendo da espécie, diferentes tipos de carragena: a Lambda (representada pela letra grega $\Lambda$ ), que é solúvel a frio e produz alta viscosidade; a Kappa (к), caracterizada pela formação de um gel rígido de alta força e quebradiço; e ainda a forma Iota (l), que apresenta um gel mais elástico com propriedades tixotrópicas. Algumas espécies de algas produzem formas mistas como, por exemplo, kappa/iota, kappa/lambda ou iota/lambda. Outras formas não tão usuais que podem ser encontradas ainda são as carragenas $\mathrm{Mu}$ e Nu. ${ }^{3}$

Dentre as diversas espécies de algas produtoras de carragena, podemos destacar a Hypnea musciformis, da qual é possível extrair a carragena do tipo kappa. Essa alga vermelha habita ambientes marinhos rasos de mares tropicais e subtropicais, podendo ser encontrada em Senegal, Vietnã, EUA, Filipinas, Índia, Brasil, Birmânia, Bangladesh e Bahamas. ${ }^{4}$ A H. musciformis é um recurso importante para o Brasil, pois é bastante utilizada na indústria de ficocoloides. ${ }^{5}$ A espécie é considerada uma alga resistente, principalmente devido a sua tolerância a amplas faixas de temperatura da água, salinidade e intensidade de luz. ${ }^{4}$

No caso da extração de polissacarídeos de algas, muito se tem utilizado algas diretamente dos bancos naturais, o que pode implicar impactos ambientais caso haja sobre-exploração. Visando ao desenvolvimento sustentável, o emprego de algas arribadas (algas dispersas pela orla da praia, muitas vezes consideradas como lixo orgânico) na produção de novos produtos, tem sido objetivo de estudo.

Neste sentido, o objetivo desta pesquisa foi avaliar o rendimento da carragena extraída de algas arribadas Hypnea musciformis, coletada na praia do Coqueiro, localizada no litoral piauiense, em função de quatro tratamentos previamente aplicados, com a finalidade do uso deste ficocoloide na produção de futuros produtos alimentícios.

\section{Material e Métodos}

As algas foram coletadas no mês de outubro (2013) na orla da Praia do Coqueiro-PI (Figura 1) e transportadas em água do mar até o Laboratório de Tecnologia do Pescado da Universidade Federal do Piauí/LATEP-UFPI. Em seguida, foram estocadas sob refrigeração $\left( \pm 5^{\circ} \mathrm{C}\right)$ em meio salino a $3 \%$ até o momento da realização dos tratamentos. Estes foram efetuados mediante a combinação de duas variáveis: secagem e branqueamento. Para o preparo das amostras foram efetuados quatro tratamentos. 


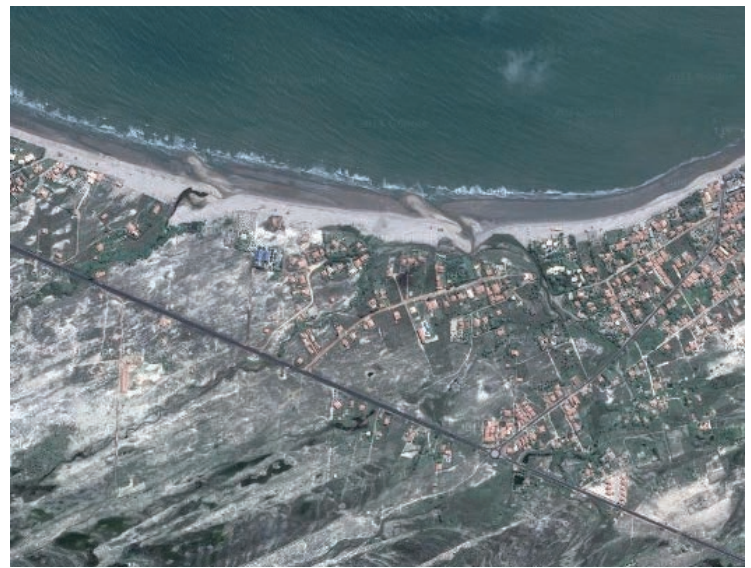

Figura 1. Imagem satélite da Praia do Coqueiro-PI (local de coleta), 2013.

Fonte: http://maps.google.com.br/

No tratamento 1 (T1), as algas foram submetidas a solução de hipoclorito de sódio na proporção de 1:1000 (v/v) por cerca de 5 minutos para branqueamento. Em seguida, foram secas a sol respeitando os horários de pico solar (12h00min às 13h30min.) por dois dias consecutivos. Tratamento 2 (T2) as algas passaram pelo mesmo processo de secagem do tratamento anterior, entretanto, na ausência da etapa de branqueamento. Os tratamentos 3 e 4 diferem-se dos descritos anteriormente em relação ao meio de secagem das amostras. No tratamento 3 (T3) A espécie da alga de interesse foi seca à estufa à $45^{\circ} \mathrm{C}$ por 20 horas, tendo sido previamente ministrado o processo de branqueamento, enquanto que no tratamento 4 (T4) as algas foram secas nas mesmas condições que o tratamento 3, porém, na ausência da etapa de branqueamento, (Figura 2).

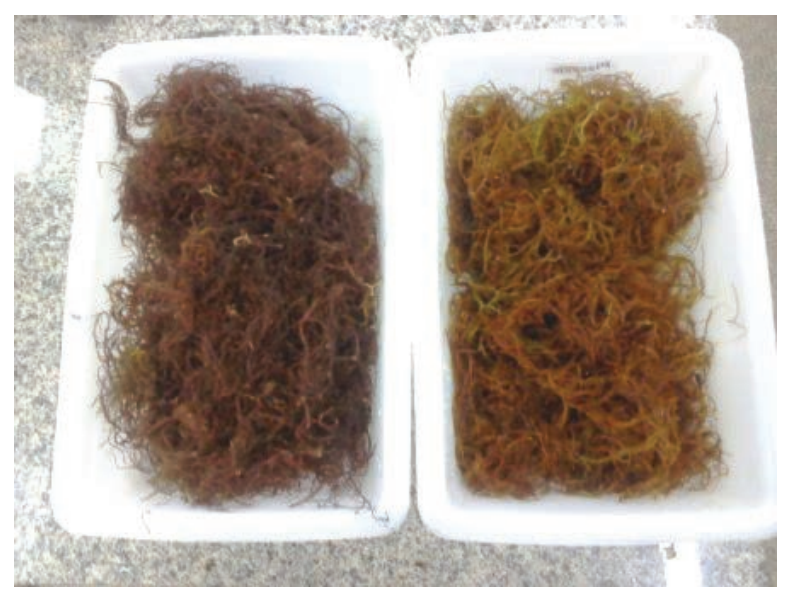

Figura 2. Algas ministradas à etapa de branqueamento (direita) e na ausência desta etapa (esquerda). UFPI, Campus de Parnaíba, PI, 2013. 
A extração baseou-se em um método descrito na literatura, ${ }^{1}$ mas com algumas modificações: Inicialmente, foi pesado lg da alga seca, após tratamento prévio, para cada estudo realizado. Em seguida, as amostras foram tratadas com solução alcalina de $\mathrm{NaOH} 0,1 \mathrm{M}$ por uma hora e meia. Dado tempo de espera, as algas foram lavadas em água corrente (destilada) até pH 7,0 Após neutralização do $\mathrm{pH}$, as mesmas foram submetidas a extração em $50 \mathrm{ml}$ de água destilada por uma hora sob temperatura de $85^{\circ} \mathrm{C}$. Terminada a extração, o material obtido foi filtrado, e desprezou-se o sólido. O filtrado recolhido foi precipitado em $30 \mathrm{ml}$ de solução de álcool etílico (P.A. 99\%) na proporção de 2:1(v/v), e levado para estufa a $70^{\circ} \mathrm{C}$ para secagem até peso constante.

Todas as análises foram realizadas em triplicata, com uma repetição para maior confiabilidade dos resultados obtidos.

Para o cálculo de rendimento da carragena, foi utilizada a metodologia matemática de regra de três simples. Os resultados obtidos da observação dos tratamentos aplicados foram tratados estatisticamente, utilizando-se a análise de variância (ANOVA) ao nível de 5\% de probabilidade pelo Teste de Tukey, visando detectar uma possível semelhança na comparação das médias com o auxílio do programa estatístico Excel.

\section{Resultados e Discussão}

os resultados obtidos referentes ao rendimento da carragena estudada nesta pesquisa estão expressos na tabela 1. Pode-se observar que o tratamento no qual a secagem das amostras ocorreu ao sol (T1 e T2) proporcionou maiores teor de gel adquirido durante os processos de extração para as algas não branqueadas, obtendo-se rendimento de 21,33\%. A etapa de branqueamento ministrada no tratamento 2 (T2) reduziu o percentual da carragena extraída, apresentando rendimento de 15,99\%. Os tratamentos nos quais as algas foram secas em estufa a $45^{\circ} \mathrm{C}$ ( T3 e T4) também mostraram menores valores de rendimento, quando comparados com aqueles referentes aos tratamentos T1 e T2. As algas secas em estufa que foram branqueadas (T3) apresentaram apenas 13,88\% de rendimento, enquanto que aquelas que não passaram por esta etapa (T4) mostraram maior rendimento de carragena, de $17,70 \%$. Pode-se observar que para esse tipo de extração não é interessante a etapa de branqueamento das algas, pois provavelmente haja perda do gel durante esse processo (tabela 1) 
Tabela 1. Resultados médios do rendimento de extração de carragena em Hypnea musciformis em função do tratamento aplicado. Parnaíba-PI, 2013.

\begin{tabular}{c|c|c|c}
\hline $\begin{array}{c}\text { Tratamentos } \\
(\mathrm{T})\end{array}$ & $\begin{array}{c}\text { Peso da alga seca } \\
(\mathrm{g})\end{array}$ & $\begin{array}{c}\text { Peso da carragena } \\
(\mathrm{g})\end{array}$ & $\begin{array}{c}\text { Rendimento } \\
(\%)\end{array}$ \\
\hline T1 & $1,01 \pm 0,004$ & $0,16 \pm 0,021$ & $15,99 \pm 2,108$ \\
T2* & $1,01 \pm 0,004$ & $0,22 \pm 0,033$ & $21,63 \pm 3,292$ \\
T3 & $1,01 \pm 0,004$ & $0,14 \pm 0,024$ & $13,89 \pm 2,425$ \\
T4 & $1,02 \pm 0,004$ & $0,18 \pm 0,029$ & $17,71 \pm 2,850$ \\
\hline
\end{tabular}

Notação (*): Valores significativos ao nível de $\mathrm{p}<0,05 \%$

Foram verificadas diferenças significativas $(\mathrm{p}<0,05 \%)$ em relação ao rendimento obtido em função dos tratamentos aplicados, sendo identificado que o tratamento 2 (T2) foi aquele que apresentou melhor eficácia para o processo de obtenção de carragena.

Em relação aos valores encontrados, é importante ressaltar que o rendimento do ficocoloide extraído de determinada espécie de alga pode variar em função da sazonalidade, época do ano, e fatores abióticos como luz, temperatura, salinidade, dentre outros. ${ }^{6}$ Dessa forma, pretende-se realizar, em futuros estudos, o cálculo do rendimento da carragena extraída da H. musciformis e sua relação com os parâmetros físico-químicos do ambiente, bem como a época do ano.

\section{Conclusões}

As amostras de algas Hypnea musciformis arribadas utilizadas para extração de carragena apresentaram valores de rendimento variando em função da forma de secagem e etapa de branqueamento. No entanto, aquelas submetidas ao branqueamento obtiveram menor rendimento em relação àquelas que não passaram por este processo.

Sob as condições desta pesquisa, as algas secadas em ambiente natural e não branqueadas concentraram maior teor de carragena. 


\section{Referências}

1. Andrade CT, Azero EG, Gonçalves MP. Rheological properties of mixtures of $x$-carrageenan from Hypnea musciformis and galactomannan from Cassia javanica. Int. J. Biol. Macromol. 2000; 27(5):349-353.

2. Girod S, Boissiére M, Longchambon K, Begu S, Pètheil CT, Devoissele JM. Polyelectrolyte complex formation between iota-carrageenan and poly (L-lysine) in dilute aqueous solutions: a spectroscopic and conformational study. Carbohydrate Polymers. 2004; 55(1):37-45.

3. Viana AG, Noseda MD, Duarte MER, Cerezo AS. Alkali modification of carrageenans. Part V. The iota-nu hybrid carrageenan from Eucheuma denticulatum and its cyclization to iota-carrageenan. Carbohydrate Polymers. 2004; 58(4):455-460.

4. Ganesan M, Thiruppathi S, Bravanath J. Mariculture of Hypnea musciformis (Wulfen) Lamouroux in South east coast of India. Aquaculture 2006; 256(1-4): 201-211.

5. Bravin IC, Yoneshique-Valentin Y. Influência de fatores ambientais sobre o crescimento in vitro de Hypnea musciformis (Wulfen) Lamouroux (Rhodophyta). Rev. Bras. Bot. 2002; 25(4):469-474.

6. Cunha SR, Pazeto FD, Crestani DEV, Lima GB, Nascimento J, Sant'anna F, et al. Potencial de Crescimento de macroalgas cultiváveis presentes na enseada de armação do Itapocoroy (Penha, SC): avaliação preliminar. Brazilian Journal of Aquatic Science and Technology. Notas Téc. Facimar 1999; 3: 17-25.

Recebido: 26/5/2014

Revisado: 18/8/2014

Aprovado: 04/10/2014 
